\title{
EVALUATION OF METAL CONTAMINANTS OF SURFACE WATER SOURCES IN AN ACTIVE PB-ZN MINE PIT AND A NEARBY POND: COMPARISON OF LEVELS OF CONTAMINATION
}

\author{
S. O. NGELE, E. J. ITUMOH AND U. OBINI \\ (Received 20 November 2014; Revision Accepted 21 January 2015)
}

\begin{abstract}
This study evaluated the potential health risks associated with domestic use of surface water from an active $\mathrm{Pb}-\mathrm{Zn}$ mine pit, compared to a nearby pond. The concentrations of $\mathrm{Pb}, \mathrm{Zn}, \mathrm{Mn}, \mathrm{Co}, \mathrm{Cu}, \mathrm{Ni}$ and $\mathrm{Cr}$ were quantitatively determined in water samples collected from Enyigba $\mathrm{Pb}-\mathrm{Zn}$ mine and a nearby Uruva pond using atomic absorption spectrophotometer. The results showed varying concentrations of these metals in the samples. The mean values of the metals $(\mathrm{mg} / \mathrm{L})$ in the samples from the pit mine (in bracket from Uruva pond) are $\mathrm{Pb}-0.80(0.50), \mathrm{Zn}-0.14(0.08)$ , $\mathrm{Mn}-0.20(0.16)$, Co - 0.07 (0.07), $\mathrm{Cu}-0.30(0.12), \mathrm{Ni}-0.31(0.80)$ and $\mathrm{Cr}-0.19(0.23)$. When compared with World Health Organisation (WHO) recommended limits for metals in drinking water, the values of $\mathrm{Pb}, \mathrm{Mn}, \mathrm{Ni}$ and $\mathrm{Cr}$ exceeded the limits in both samples while the values of $\mathrm{Zn}, \mathrm{Cu}$ and $\mathrm{Co}$ were below the limits. The levels of significant differences in the sources of concentrations of the metals in both samples were tested at $95 \%$ confidence level ( $\alpha=$ $0.05)$ using $F$ - and student's $t$-tests. It showed no evidence of differences $\left(t_{\text {exps }}<t_{\text {crits }}\right.$ ), suggesting that the metal contamination of the water samples originated from common sources, such as the soil geochemistry of the area
\end{abstract}

KEYWORDS: metal contamination, $\mathrm{Pb}-\mathrm{Zn}$ mining, surface water, Enyigba mine pit, Uruva pond

\section{INTRODUCTION}

There has been growing concern about the health and environmental risks associated with high levels of metal deposits in our environment. This is because metals are persistent environmental pollutant (Stoica, 1999; Monperrus, et al., 2005) and their presence is a major threat to health due to their bio-accumulating tendency and toxicity (Thomas et al. 2008). Mining operations and mine waste materials contribute major quantities of metals to soils, plants, waters and sediments (Lee et al., 2009). In Enyigba $\mathrm{Pb}-\mathrm{Zn}$ mine district, mining dates back to 1925 and has continued since after the Nigerian Civil War (Farrington, 1952). As a result, excess water from the pits are usually pumped out to the unsuspecting villagers, who have little or no concern about the health risks associated with such water use (Nnabo et al., 2011). Apart from the mining operations which serve as a source of metals in the water, clastic movement through wind and storm can transport these toxic metals to the soils, plants, waters and sediments in the vicinity of mine pits (Itumoh et al., 2011; Lee et al., 2009). Therefore, this study evaluated the levels of metal contamination in surface water from Enyigba $\mathrm{Pb}-\mathrm{Zn}$ mine pit and the nearby Urava pond. The aim of the study was to compare the levels of statistical significance differences between the concentrations of metals in two surface waters.

\section{EXPERIMENTAL SECTION}

\section{Background of the study area}

The study area, Enyigba, in Ebonyi State, South-eastern Nigeria (Fig. 1) is situated about $13 \mathrm{~km}$ South of Abakaliki metropolis. The area is bounded by latitude $6^{0}$ $09^{1}$ to $6^{0} 14^{1} \mathrm{~N}$, longitude $8^{0} 05^{1} \mathrm{E}$ to $8^{0} 10^{1} \mathrm{E}$. The topography of the area is generally undulating with low and high reliefs marked by undulating range of shale outcrops, which serves as the host for mineral ore bodies such as $\mathrm{Pb}-\mathrm{Zn}, \mathrm{Cu}$ and brine. The whole area is within the Abakaliki anticlinorium and generally underlain by shales with $60 \mathrm{~m}$ and $30 \mathrm{~m}$ as its highest and lowest elevations respectively above sea level (Nnabo et al., 2011). The area falls within the rainforest climatic region of South-Eastern Nigeria where the rainy season spans from April to October and the dry season from October to April. The average annual rainfall of the study area is about $1500 \mathrm{~mm}$ with actual surface temperature (seasonal temperature) of between $24-36{ }^{\circ} \mathrm{C}$ during dry season and about $18{ }^{\circ} \mathrm{C}$ during the rainy season. The study area is of high leached red soils of tropical forest areas with the vegetation dominated by grasses, shrubs and trees e.g. palm trees, coconut, mango, and orange trees (Omaka et al., 2014)

S. O. Ngele, Department of Industrial Chemistry, Ebonyi State University Abakaliki, Nigeria

E. J. Itumoh, Department of Industrial Chemistry, Ebonyi State University Abakaliki, Nigeria

U. Obini, Department of Industrial Chemistry, Ebonyi State University Abakaliki, Nigeria 


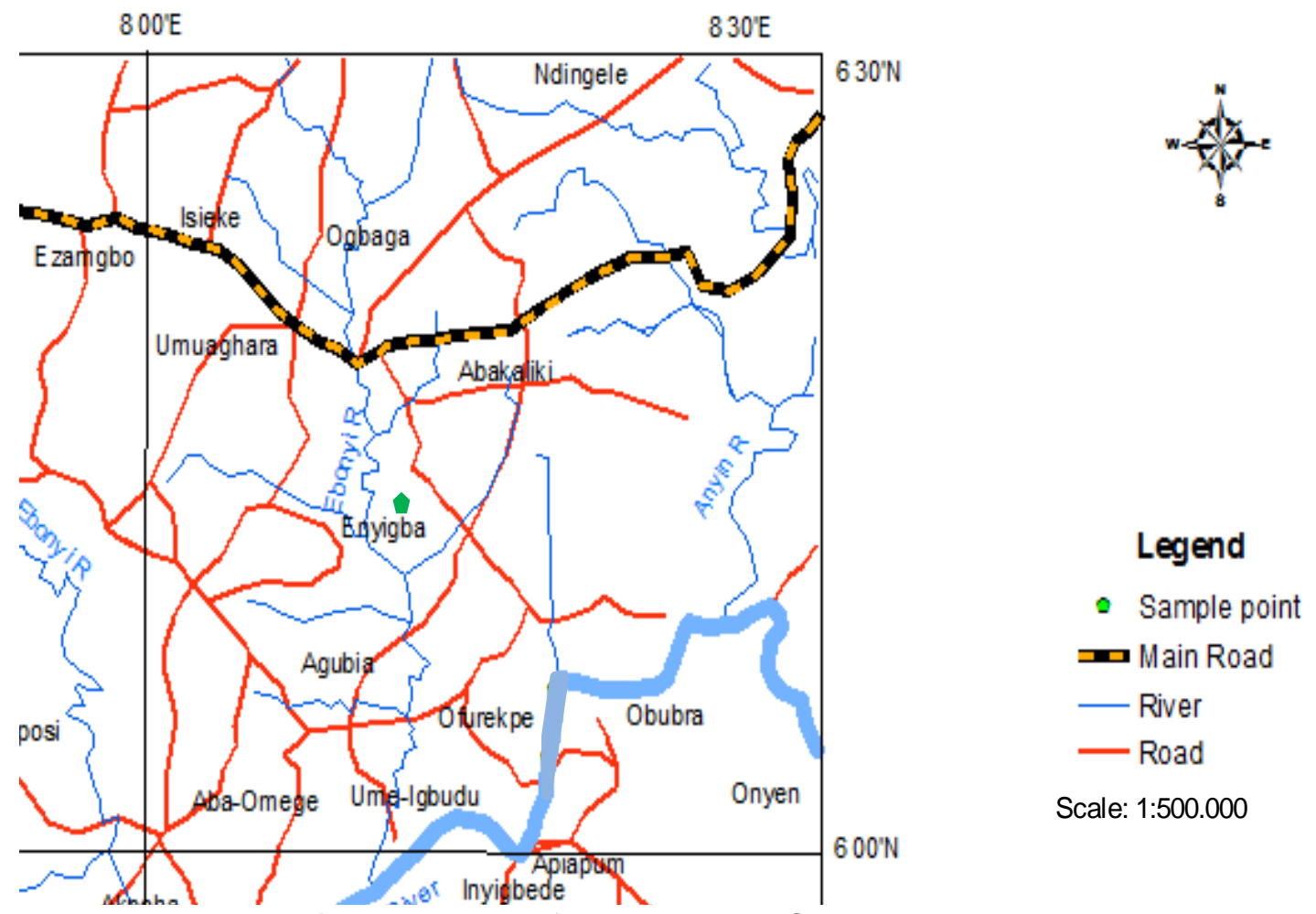

Fig. 1. The map of the study area, South-eastern Nigeria

\section{Sampling protocols and analysis}

All glassware, high-density polyethylene (HDPE) storage bottles for reagent solutions and plastic items were acid cleaned following a standard procedure. All items for collecting and storing samples and reagents were first washed with distilled deionised water (DDW), soaked overnight in $10 \%(\mathrm{v} / \mathrm{v})$ nitric acid and then rinsed exhaustively with DDW. The washed items were dried and stored in zip locked polyethylene bags (Pistón et al., 2012). Water samples were collected for a period of three weeks. The cleaned HDPE bottles were used for sampling and storage of water samples at $4^{\circ} \mathrm{C}$. The samples were acidified with nitric acid (Battey and Gardner, 1977). The samples were kept in the refrigerator upon return to the laboratory and analysed within one hour of collection and maximum of $24 \mathrm{~h}$. The metallic contents of the samples were determined using atomic absorption spectrophotometer (AAS) (PerkinElmer Buck Scientific VGP 210) according to standard procedures (Mendham et al., 2004).

\section{Statistical analysis}

The data generated in this study were computed using Microsoft Excel Spreadsheet 2007 (Data analysis ToolPak). The F-Test Two Sample for Variances and $t$ Test Two-Sample Assuming Unequal Variances were used. The tests were done to determine if there are evidence of significant differences in the levels of contamination of the metals in the two sets of samples analyzed.

\section{RESULTS AND DISCUSSION}

The results of the mean concentrations $(\mathrm{mg} / \mathrm{L})$ of metals from the two samples are presented in Table 1. The values are compared to World Health Organisation (WHO), Guideline for Drinking Water Quality, (2011). The summary of the result is presented in Figure 1.

The concentrations of $\mathrm{Pb}, \mathrm{Mn}, \mathrm{Ni}$ and $\mathrm{Cr}$ found in water samples from the mine pit were above the WHO guideline. Conversely, $\mathrm{Zn}$ and $\mathrm{Cu}$ were detected at concentrations below the guideline in the sample.

The concentrations of the metals from the Uruva pond showed a similar trend with those from the mine pit. $\mathrm{Pb}, \mathrm{Mn}, \mathrm{Ni}$, and $\mathrm{Cr}$ were above the guideline, while $\mathrm{Zn}$ and $\mathrm{Cu}$ were below the guideline. Although, the concentrations of $\mathrm{Pb}, \mathrm{Zn}, \mathrm{Mn}$ and $\mathrm{Cu}$ in the Uruva pond were less than the concentrations of the same metals detected in the samples from the mine pit, the concentration of Co were the same $(0.07 \mathrm{mg} / \mathrm{L})$, while the concentrations of $\mathrm{Ni}$ and $\mathrm{Cu}$ were higher than those of the samples from the mine pit.

In all the samples, $\mathrm{Pb}$ and $\mathrm{Ni}$ gave the highest concentrations of $0.80 \mathrm{mg} / \mathrm{L}$, followed by $\mathrm{Cu}(0.30$ $\mathrm{mg} / \mathrm{L}), \mathrm{Cr}(0.23 \mathrm{mg} / \mathrm{L}), \mathrm{Mn}(0.20 \mathrm{mg} / \mathrm{L}), \mathrm{Zn}(0.14 \mathrm{mg} / \mathrm{L})$ and $\quad \mathrm{Cr} \quad$ (0.07). 
Table 1: The mean concentrations of the metals in the two samples compared to WHO guideline

\begin{tabular}{llllllll}
\hline Sample & $\mathrm{Pb}$ & $\mathrm{Zn}$ & $\mathrm{Mn}$ & $\mathrm{Co}$ & $\mathrm{Cu}$ & $\mathrm{Ni}$ & $\mathrm{Cr}$ \\
\hline Mine pit water & 0.80 & 0.14 & 0.20 & 0.07 & 0.30 & 0.31 & 0.19 \\
Uruva pond & 0.50 & 0.08 & 0.16 & 0.07 & 0.12 & 0.80 & 0.23 \\
WHO Guideline & 0.01 & 3.00 & 0.05 & 0.00 & 2.00 & 0.02 & 0.05 \\
\hline
\end{tabular}

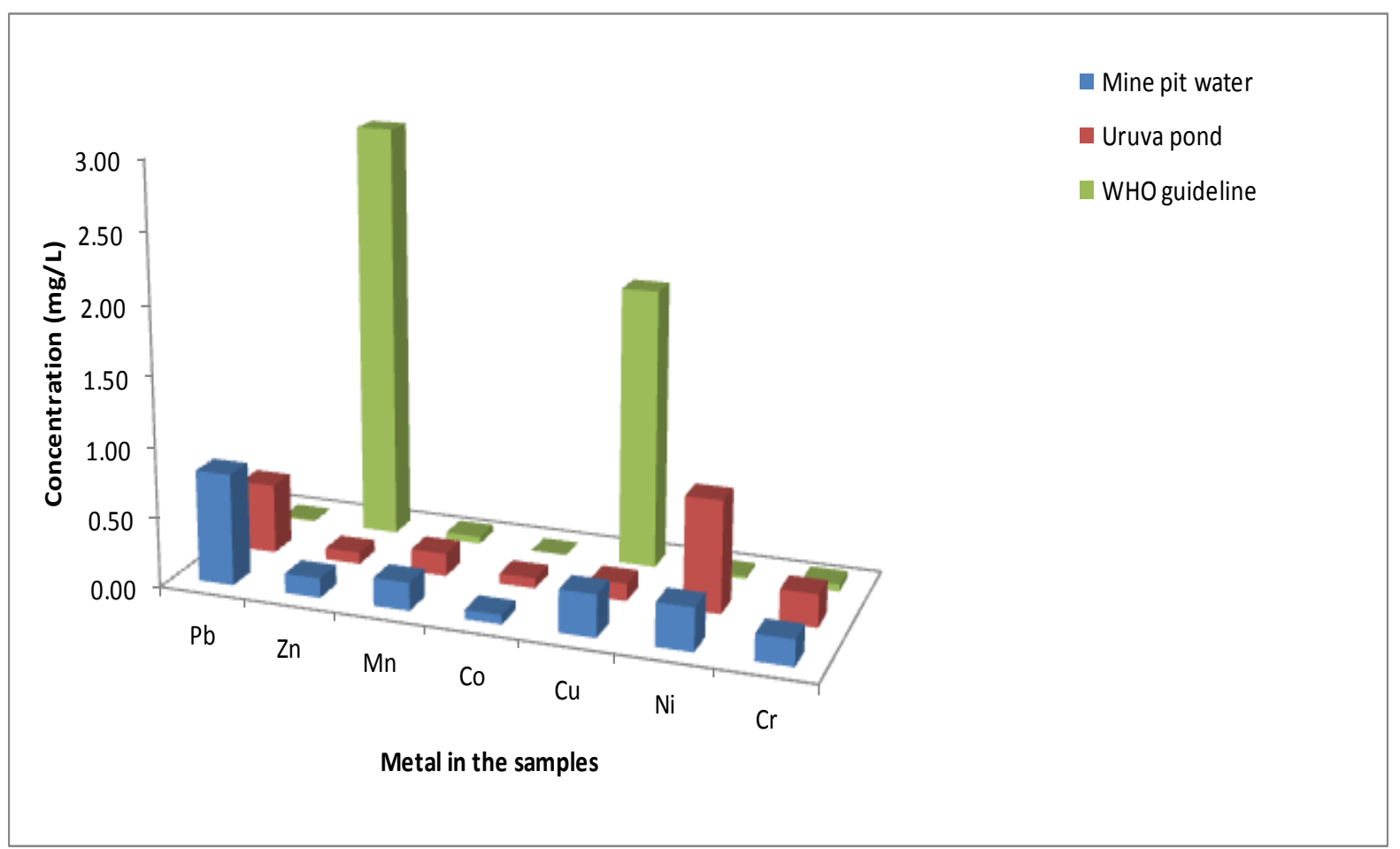

Fig. 2. The graphical representation of the concentrations of the metals in the samples, compared to WHO guideline

\section{Significance Tests}

The levels of significant differences in the concentration of the metals in the two samples were tested at $95 \%$ confidence level $(\alpha=0.05)$ using $F$ - and student's $t$-tests. The $F$-test was used to determine whether the variances for the concentrations of the metals in the samples are equal or unequal. The null hypothesis was that the variances are equal, mine pit water = Uruva pond and the alternative hypothesis was that the variances are not equal, mine pit water $\neq$ Uruva pond. Afterwards, an unpaired $t$-test assuming Unequal Variance was computed. The null hypothesis was that there is no difference between the means, mine pit water = Uruva pond and the alternative hypothesis was that there was a difference between the means, mine pit water $\neq$ Uruva pond. The results showed that the $F_{\text {exps }}$, which is 0.67 , is greater than $F(0.05,6,5)$, which is 0.17 $\left(F_{\text {exps }}>F_{\text {crits }}\right)$. Hence, the alternative hypothesis was retained that there was evidence of differences between the variances at an $\alpha=0.05$. The result of the $t$-test showed that $t_{\text {exps }}$, which is -0.03 , is less than $t(0.05,10)$, which is $2.63\left(t_{\text {exps }}<t_{\text {crits }}\right)$. Therefore, we concluded with the null hypothesis that there was no evidence of differences between the means at an $\alpha=0.05$.

Statistically, the mean concentrations of the metals in both the water samples from the mine pit and Uruva pond are equal. This is indicative of the geochemistry of the sampled area, which is a $\mathrm{Pb}-\mathrm{Zn}$ mine district of West Africa (Nnabo et al., 2011). The presence of other metals may be attributed to the nature of gangue minerals which occur in association with $\mathrm{Pb}$ $\mathrm{Zn}$ mineralization of Enyigba district. The presence of these metals in the samples could have also been influence by the oxidation of pyrite $\left(\mathrm{FeS}_{2}\right)$ and other sulphides which results in the release of hydrogen ions that lower the $\mathrm{pH}$ levels of water samples and increases the concentrations of sulphates and metals such as $\mathrm{Fe}$, $\mathrm{Cu}, \mathrm{Pb}, \mathrm{Zn}, \mathrm{Cd}$ and $\mathrm{Ni}$.

\section{Similar studies}

The observed mean concentrations of metal contaminants in surface water in this study were compared with other reports in previous studies conducted in other parts of the world. A study in Tarkwa area of Ghana showed a lower concentration of $\mathrm{Pb}(0.65$ $\mathrm{mg} / \mathrm{L})$, but higher concentrations of $\mathrm{Cu}(0.93 \mathrm{mg} / \mathrm{L}), \mathrm{Mn}$ $(0.34 \mathrm{mg} / \mathrm{L})$, and $\mathrm{Zn}(0.30 \mathrm{mg} / \mathrm{L})$ (Armah et al., 2010). A study of a limestone mining site in Sokoto State, NW of Nigeria showed similar concentration of $\mathrm{Zn}(0.29 \mathrm{mg} / \mathrm{L})$, far lower concentration of $\mathrm{Pb}(0.001 \mathrm{mg} / \mathrm{L})$, while $\mathrm{Mn}, \mathrm{Ni}$ and $\mathrm{Cu}$ were not detected. An assessment of metal contamination in an abandoned mines of Han River Watershed, Korea showed that the water samples contained high contents $\mathrm{Cu}, \mathrm{Pb}$, and $\mathrm{Zn}$, exceeding the fresh water acute and chronic criteria (Lee et al., 2009).

\section{CONCLUSION}

The results of the mean concentrations $(\mathrm{mg} / \mathrm{L})$ of metals from the two samples compared to World Health 
Organisation (WHO), Guideline for Drinking Water Quality, (2011) showed that the the concentrations of $\mathrm{Pb}, \mathrm{Mn}, \mathrm{Ni}$ and $\mathrm{Cr}$ found in the water samples from the mine pit were above the $\mathrm{WHO}$ guideline. Conversely, $\mathrm{Zn}$ and $\mathrm{Cu}$ were detected at concentrations below the guideline in the sample. The concentrations of the metals from the Uruva pond showed a similar trend with those from the mine pit. There was no statistical level of significance difference between the mean concentrations of metals in the water samples from the mine pit and the Uruva pond, which may be indicative of the area's soil geochemistry as the possible dominant source of contamination of the metals detected.

\section{ACKNOWLEDGEMENTS}

The authors are grateful to Mr. Williams for his assistance in sampling and analysis of this work.

\section{REFERENCES}

Armah, F. A., Obiri, S., Yawson, D. O., Pappoe, A. N and Bismark, A., 2010. Mining and Heavy Metal Pollution: Assessment of Aquatic Environments in Tarkwa (Ghana) using Multivariate Statistical Analysis. Journal of Environmental Statistics, 1, (4): 1-13.

Battey, G. E and Gardner, D., 1977. Sampling and Storage of Natural Waters for Trace Metal Analysis. Water Research, 11, (9): 745-756.

Farrington, J. L., 1952. A Preliminary Description of the Nigerian $\mathrm{Pb}-\mathrm{Zn}$ Field. Econ. Geol., 47, 583-608.

Itumoh, E. J., Izuagie, T., Omaka, N. O., Uba, A., Shuaibu, M., Dogonyaro, I. A and Isah, S., 2011. Trace Metals Analysis of Soil and Water from a Limestone Mining Site in Sokoto State Nigeria. Journal of Physical Science and Innovations, 3, 62-71.

Lee, H., Kabir, M. I., Kwon, P. S., Kim, J. M., Kim, J. G., Hyun, S. H and Jung, M. S., 2009. Contamination Assessment of Abandoned Mines by Integrated Pollution Index in the Han River Watershed. The Open Environmental Pollution \& Toxicology Journal, 1, 27-33.

Mendham, J., Denney, R. C., Barnes, J. D and Thomas, M., 2004. Vogel's Textbook of Quantitative Chemical Analysis (6th ed.). Delhi, India: Pearson Education Ltd.
Monperrus, M., Point, D., Grail, J., Chauvand, L., Amouroux, D., Bareille, G. and Donard, O., 2005. Determination of Metal and Organometal Trophic Bioaccumulation in the Benthic Macrofauna of the Adour Estuary Coastal Zone (SW France, Bay of Biscay). J. Environmental Monitoring, 7, 693-700.

Nnabo, P. N., Orazulke, D. M and Offor, O. C., 2011. The Preliminary Assessment of the Level of Heavy Elements Contaminations in Stream Bed Sediments of Enyigba and Environs, South Eastern Nigeria. Journal of Basic Physical Research, 2, (2): 43-52.

Omaka, O. N., Nwabue, F. I., Itumoh, E. J., Oroke, E. C and Igwe, D. O., 2014. Physicochemical Parameters and nutrients Variations of Streams and Rivers in Abakaliki, Ebonyi State, Nigeria. Global NEST Journal, 16, (1): 114-123.

Pistón, M., Silva, J., Pérez-Zambra, R., Dol, I and Knochen, M., 2012. Automated Method for the Determination of Total Arsenic and Selenium in Natural and Drinking Water by HG-AAS. Environmental Geochemistry and Health, 34, (2): 273278.

Stoica, A., 1999. Analytical Studies of the Pollution of Arges River. Critical Reviews in Analytical Chemistry, 29, (3): 243-247.

Thomas, A. J., Niveta, J., Joshi, H. C and Prasad, S., 2008. Agricultural and Agroprocessing Wastes as Low Cost Adsorbents for Metal Removal from Wastewater: A Review. J. Scientific \& Industrial Research, 67, 647-658.

World Health Organisation (WHO)., 2011. Guidelines for Drinking-water Quality. Geneva: World Health Organisation (WHO). 
